\title{
Low dose environmental radon exposure and breast tumor gene expression
}

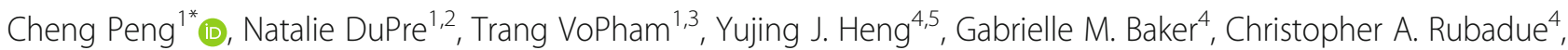
Kimberly Glass ${ }^{1}$, Abhijeet Sonawane ${ }^{1}$, Oana Zeleznik ${ }^{1}$, Peter Kraft ${ }^{3,6}$, Susan E. Hankinson ${ }^{1,3,7}$, A. Heather Eliassen ${ }^{1,3}$, Jaime E. Hart ${ }^{1,8}$, Francine Laden ${ }^{1,3,8+}$ and Rulla M. Tamimi ${ }^{1,3+}$

\begin{abstract}
Background: The International Agency for Research on Cancer classified radon and its decay-products as Group-1human-carcinogens, and with the current knowledge they are linked specifically to lung cancer. Biokinetic models predict that radon could deliver a carcinogenic dose to breast tissue. Our previous work suggested that low-dose radon was associated with estrogen-receptor (ER)-negative breast cancer risk. However, there is limited research to examine the role of radon in breast cancer biology at the tissue level. We aim to understand molecular pathways linking radon exposure with breast cancer biology using transcriptome-wide-gene-expression from breast tumor and normal-adjacent tissues.
\end{abstract}

Methods: Our study included 943 women diagnosed with breast cancer from the Nurses' Health Study (NHS) and NHSII. We estimated cumulative radon concentration for each participant up-to the year of breast cancer diagnosis by linking residential addresses with a radon exposure model. Transcriptome-wide-gene-expression was measured with the Affymetrix-Glue-Human-Transcriptome-Array-3.0 and Human-Transcriptome-Array-2.0. We performed covariate-adjusted linear-regression for individual genes and further employed pathway-analysis. All analyses were conducted separately for tumor and normal-adjacent samples and by ER-status.

Results: No individual gene was associated with cumulative radon exposure in ER-positive tumor, ER-negative tumor, or ER-negative normal-adjacent tissues at FDR $<5 \%$. In ER-positive normal-adjacent samples, PLCH2reached transcriptome-wide-significance (FDR $<5 \%)$. Gene-set-enrichment-analyses identified 2-upregulated pathways (MAPK signaling and phosphocholine biosynthesis) enriched at FDR $<25 \%$ in ER-negative tumors and normal-adjacent tissues, and both pathways have been previously reported to play key roles in ionizing radiation induced tumorigenesis in experimental settings.

Conclusion: Our findings provide insights into the molecular pathways of radon exposure that may influence breast cancer etiology.

Keywords: Low-dose radon, Tumor gene expression, Breast cancer risk

\footnotetext{
* Correspondence: recpe@channing.harvard.edu

†Francine Laden and Rulla M. Tamimi contributed equally to this work.

${ }^{1}$ Channing Division of Network Medicine, Brigham and Women's Hospital, Boston, MA, USA

Full list of author information is available at the end of the article
}

(C) The Author(s). 2020 Open Access This article is licensed under a Creative Commons Attribution 4.0 International License, which permits use, sharing, adaptation, distribution and reproduction in any medium or format, as long as you give appropriate credit to the original author(s) and the source, provide a link to the Creative Commons licence, and indicate if changes were made. The images or other third party material in this article are included in the article's Creative Commons licence, unless indicated otherwise in a credit line to the material. If material is not included in the article's Creative Commons licence and your intended use is not permitted by statutory regulation or exceeds the permitted use, you will need to obtain permission directly from the copyright holder. To view a copy of this licence, visit http://creativecommons.org/licenses/by/4.0/. The Creative Commons Public Domain Dedication waiver (http://creativecommons.org/publicdomain/zero/1.0/) applies to the data made available in this article, unless otherwise stated in a credit line to the data. 


\section{Background}

Radon-a natural radioactive gas originating from the decay series of uranium found in the Earth's crust-accounts for a significant proportion of the annual effective dose of natural radioactivity [1], and have been extensively studied in relation lung cancer [2]. Radon is fat-soluble, tends to bio-accumulate in tissues with higher fat content such as the breast, has a relatively short half-life ( 3.8 days), and undergoes rapid decay processes to emit alpha particles that may interact with biological tissues and macro-molecules [3, 4]. Similar to other ionizing radiation, radon and its decay products are mutagenic [4], as they could lead to single and double-strand DNA breaks [5], pyrimidine dimer formations [6], intra- and inter-chromosomal aberrations [7, 8] sister chromatid exchange $[9,10]$ micronuclei formation [11] and eventually genomic instability [5]. Residential radon exposures were associated with increased lung cancer risk among never smokers who carried genetic polymorphisms in DNA-repair genes [12]. Chromosomal abnormality was also observed in lung cancer patients exposure to radon and air pollution [13]. In areas with high radon background, increased levels of indoor radon concentrations were associated with chromosomal translocation and aberrations [14, 15]. Although limited by the number of cases, a suggestive association was observed between residential radon and higher risk of breast cancer, in a radon-prone area [16]. In the Nurses' Health Study II (NHSII), VoPham et al. conducted a prospective analysis of radon exposure and incidence of invasive breast cancer, and demonstrated that cumulative radon exposure, even at low doses, was associated with higher risk of estrogen receptor (ER)-negative breast cancer [17]. However, the molecular mechanisms underlying the effects of radon on breast cancer risk are not fully understood. A better understanding of the biological pathways associated with low dose radon in population-based studies may provide important human evidence supporting the role of environmental exposure in breast carcinogenesis.

The study of transcriptome-wide gene expression profiling in breast tumor and normal-adjacent tissue offers a unique opportunity to uncover biological mechanisms linking environmental exposures such as radon and breast cancer risk. The breast tissue-specific transcriptome provides deep coverage of measurable mRNA transcripts, and provides a quantitative and systematic readout of the pathophysiological status of breast tissue that reflects the complex interplay between genetics and both endogenous and exogenous environmental influences. In breast cancer cell lines, ionizing radiation leads to differential gene expression in pathways related to apoptosis [18, 19] inflammation [19] oxidative stress [19, 20] DNA damage and repair $[12,19]$ and cell cycle regulation [19]. As tissue specific transcriptomes capture detailed levels of molecular activities, transcriptomic analyses of breast tumor and normal-adjacent tissues may provide a comprehensive assessment of biological mechanisms underlying radon related carcinogenesis.

In two large-scale prospective cohort studies in the United States, we investigated the association between radon concentrations at the participants' addresses-estimated as cumulative averages up to the year of breast cancer diagnosis-and transcriptome-wide gene expression in breast tumor and normal-adjacent tissues. We hypothesized that breast cancer cases living in areas of higher radon concentration would have differential gene expression patterns in tumor and normal-adjacent tissues compared with women living in areas of lower concentrations. While differences in gene expression signatures in tumor tissues may provide information about radon-associated tumor initiation and progression; alterations in gene expression patterns in normaladjacent tissues may reflect a larger field effect in the breast before carcinogenesis.

\section{Methods \\ Study population}

Our study includes participants from the Nurses' Health Study (NHS) and the NHSII-both of which are large-scale prospective longitudinal cohorts of registered female nurses in the U.S. The NHS was established in 1976, when 121,701 women aged 30-55 years, completed and returned an initial questionnaire. In 1989, the NHSII was initiated, which enrolled 116, 429 women, ages 25-42 years, who completed and returned an initial questionnaire. Participants have been followed via questionnaires mailed biennially to update information on exposure variables and ascertain outcomes [21]. The cumulative follow-up rates for NHS and NHSII were both greater than 90\% [22]. Cases of invasive breast cancer were identified by participants' responses to the biennial questionnaires from the start of follow-up (1976 NHS; 1989 NHSII) through 2012. Following a reported diagnosis, study investigators requested permission to review the participant's medical records to confirm the diagnosis. Over 99\% of breast cancer diagnosis were confirmed upon medical record review. For deceased participants, we contact next-of-kin for record review permission or link to cancer registries. With permission, we linked $96 \%$ of breast cancer cases to relevant medical records. The study protocol was approved by the institutional review boards of the Brigham and Women's Hospital and Harvard T. H. Chan School of Public Health, and those of participating registries as required. 


\section{Radon estimation}

We collected participants' residential addresses from biennial questionnaires updated since initial enrollment in NHS (1976) and NHSII (1989). Residential addresses were geocoded and spatially linked to the Laurence Berkeley National Laboratory U.S. county-level indoor radon exposure model using a geographic information system (GIS) ArcMap 10.3.1 (Esri, Redlands, CA) [17]. The radon exposure model was estimated using a Bayesian mixed-effect regression to predict annual average county-level radon concentrations derived from the short-term Environmental Protection Agency (EPA)/ State Residential Radon Survey (SRRS) and long-term National Residential Radon Survey (NRRS) [23, 24]. We calculated radon concentration as a time-varying cumulative average for each participant, where radon concentrations from years prior to diagnosis were averaged and updated biennially until a breast cancer diagnosis [17]. Radon concentration was expressed as $\mathrm{pCi} / \mathrm{L}$ based on the scale established by the EPA $\left(1 \mathrm{pCi} / \mathrm{L}=37 \mathrm{~Bq} / \mathrm{m}^{3}\right.$ international unit).

\section{Gene expression measurements}

We began to collect archived formalin-fixed paraffinembedded breast cancer blocks for participants with primary incident breast cancer since 1993. Formalin fixed paraffin-embedded (FFPE) tumor blocks were retrieved from the pathology departments of treating hospitals [25]. We were able to obtain tissue microarrays (TMAs) from 5561 NHS and NHSII participants (Dana Farber / Harvard Cancer Center Tissue Microarray Core Facility, Boston, MA) [25, 26]. Prioritizing women with existing genetic and circulating biomarker measurements, we were able to perform tissue gene expression microarrays among 954 breast cancer cases. Participant characteristics were similar among breast cancer cases with and without gene expression measurement [27]. We extracted RNA from multiple cores of 1 or $1.5 \mathrm{~mm}$ taken from tumor ( $n=1-3$ cores) and normal-adjacent $(n=3-$ 5 cores) tissues using the Qiagen AllPrep RNA isolation kit for FFPE. Normal-adjacent tissues were obtained $>1$ $\mathrm{cm}$ away from the tumor edge. A detailed protocol has been published previously [28-30] (microarray data accession number: GSE115577). In brief, we measured gene expression using Affymetrix Glue Grant Human Transcriptome Array 3.0 (hGlue 3.0) for samples processed in 2012-2014 and Human Transcriptome Array 2.0 (HTA 2.0) microarray chips (Affymetrix, Santa Clara, CA, USA) for samples processed in 2015-2018. All microarrays were scanned with the GeneChip ${ }^{\circ}$ Scanner 3000 7G (Affymetrix, Santa Clara, CA, USA). We normalized gene expression data using robust multi-array average (RMA; Affymetrix Power Tools (ATP)), and performed sample quality control using Affymetrix Power
Tools probeset summarization based metrics [28, 29]. A total of 2160 FFPE samples were assayed. We excluded samples that failed quality control steps $(n=440)$, technical replicates $(n=139)$, samples with unknown IDs $(\mathrm{n}=4)$. In total, 1577 samples (882 tumor tissues and 695 normal-adjacent tissues) from 954 invasive breast cancer cases passed quality control. For genes that were mapped by multiple probes, the most variable probe was selected to represent the gene. The hGlue 3.0 platform included 18,102 genes with unique Entrez ID and the HTA 2.0 platform included 25,023 genes with unique Entrez ID. In our current analysis, we included 17,791 genes that were in common among the two platforms (70\% overlapped). We controlled for known technical variabilities (batch / plate) using ComBat-an empirical Bayes method used to control for known batch effects [31]. We further removed genes with low expression (< 25th percentile).

\section{Covariates and final dataset}

We obtained information on potential risk factors for breast cancer via the biennial NHS and NHSII questionnaires (age, body mass index (BMI), hormone therapy (HT) use) or pathological reports (year of diagnosis). Median household income and region of residence were based on linking geocoded residential addresses with data from the U.S. Census Bureau [17]. ER status was determined via central review of breast tissue microarrays [25]. To calculate pack-year smoking, we multiplied smoking duration in years by packs of cigarettes smoked per day [32]. We restricted our analysis to women with complete exposure and covariate data, resulting in 943 breast cancer cases (874 tumor tissues, 687 normaladjacent tissues; 1561 total samples; 618 tumor-normaladjacent pairs).

\section{Statistical analysis \\ Single gene analysis}

We evaluated the association of cumulative average radon concentrations and transcriptome-wide gene expression at each individual gene using covariate-adjusted linear regression via the $\mathrm{R}$ Bioconductor package linear models for microarray data (limma) [33]. County radon measurements ranged between 4 and 30. The surveys were designed using a population-based stratified random sampling scheme with the intent of being representative of the study area. Radon concentrations were dichotomized at $2 \mathrm{pCi} / \mathrm{L}(<2 \mathrm{pCi} / \mathrm{L}$ : low; $\geq 2 \mathrm{pCi} / \mathrm{L}$ : high $)$ based on the U.S. EPA Assessment of Risks from Radon in Homes that suggests remediation at $2 \mathrm{pCi} / \mathrm{L}$ based on the lifetime risk for lung cancer deaths [34, 35]. This cut point $(2 \mathrm{pCi} / \mathrm{L})$ is also in alignment with our previous findings reporting environmental radon exposure and breast cancer risk, where we observed statistically 
significant associations between radon in the highest quintile $\left(74.9 \mathrm{~Bq} / \mathrm{m}^{3}\right.$ or $\left.2.02 \mathrm{pCi} / \mathrm{L}\right)$ with ER-negative breast cancer risk [17]. As a sensitivity analysis, we modeled radon as a continuous exposure matrix. In each model, we adjusted for the following covariates selected a priori: age at diagnosis (continuous), year of diagnosis (continuous), menopausal status and HT use (postmenopausal not using / post-menopausal using / premenopausal or unknown), BMI (continuous), Census tract area-level socioeconomic status (continuous), study region (Northeast / Midwest / West / South) and surrogate variables generated from the transcriptome data (leek method) (Bioconductor sva package in R) [36]. Distributions of family, age at first birth and parity did not differ by radon exposure $(\geq 2 \mathrm{pCi} / \mathrm{L}$ vs. $<2 \mathrm{pCi} / \mathrm{L})$. We therefore did not include them in the regression models. We analyzed tumor and normal-adjacent tissues separately, and we stratified the analysis by ER status. A gene was considered to be significant transcriptome-wide if it reached the FDR-corrected $p$-value of $p_{B H}<0.05$ based on the method of Benjamini and Hochberg [37].

Among the top 10 most significant genes identified in tumor tissue, we performed sensitivity analyses and examined the associations between radon exposure and gene expression among never smokers and women smoked $>16$ pack-years (16 pack-years is the population median among ever smokers). Given the latency period of radon exposure to cancer incidence, we also restricted radon exposure 5 year prior to breast cancer diagnosis.

\section{Gene-set enrichment pathway analysis}

Using gene set enrichment analysis (GSEA) [38], we further examined for functional enrichment of biological pathways associated with radon exposure. We chose gene set databases from the Molecular Signature Database (MSigDB) (http://www.broadinstitute.org/gsea/ msigdb/), which included 217 gene sets from BioCarta, 674 gene sets from Reactome and 50 gene sets from Hallmark. We residualized the entire transcriptome matrix on variables that we adjusted for in the single gene model: age at diagnosis (continuous), year of diagnosis (continuous), menopausal status and HT use (post-menopausal not using / post-menopausal using / premenopausal or unknown), BMI (continuous) and surrogate variables. We applied phenotype based permutation (1000 times), we used the Pearson correlation coefficient as the metric for ranking genes. Specifically, we calculated Pearson correlation between radon and each gene in the transcriptome, ranked genes based on their Pearson correlations with radon, and calculated the enrichment score for the list of genes. The enrichment is the maximum deviation from zero encountered in a random walk, and is a measure of whether genes are randomly distributed throughout an a prior defined set of genes [38]. We excluded gene sets that contained either less than 15 or greater than 500 genes. We reported gene sets that are significantly enriched at a FDR threshold of less than 0.25 .

\section{Results}

\section{Participant characteristics}

One-hundred and eighty-four participants were exposed to high levels of cumulative radon $(\geq 2 \mathrm{pCi} / \mathrm{L})$, while 690 participants were exposed to low levels of cumulative radon $(<2 \mathrm{pCi} / \mathrm{L})$. Mean age at breast cancer diagnosis was slightly younger for participants in the high radon group (mean $\pm \mathrm{SD}=57.6 \pm 11.5$ years) compared to the low radon group (mean $\pm \mathrm{SD}=59.7 \pm 11.3$ years) (Table 1). We observed comparable median year of diagnosis for both groups. In the high radon group, 30\% of participants were postmenopausal and had not used HT, $32 \%$ of women were postmenopausal and used HT, while $38 \%$ were either premenopausal or did not report HT use. The proportion of women who used HT was comparable in the low radon group. Average BMI was

Table 1 Participant characteristics of women diagnosed with breast cancer in the Nurse' Health Studies who contributed to tumor data $(N=874)$

\begin{tabular}{|c|c|c|}
\hline \multicolumn{3}{|c|}{ Cumulative average annual radon concentration } \\
\hline \multirow[t]{2}{*}{ Variable } & High ( $\geq 2 \mathrm{pCi} / \mathrm{L})$ & Low $(<2 \mathrm{pCi} / \mathrm{L})$ \\
\hline & $\boldsymbol{N}=184$ & $\boldsymbol{N}=690$ \\
\hline Age at diagnosis (year) [mean (SD)] & $57.6(11.5)$ & $59.7(11.3)$ \\
\hline Year of diagnosis [median (IQR)] & $2000(8)$ & $1999(8)$ \\
\hline \multicolumn{3}{|l|}{ Cohort [n (\%)] } \\
\hline NHS & $100(54 \%)$ & $431(62 \%)$ \\
\hline NHSII & $84(46 \%)$ & $259(38 \%)$ \\
\hline \multicolumn{3}{|c|}{ Menopausal status / menopausal hormone therapy ${ }^{a}[\mathrm{n}(\%)]$} \\
\hline Postmenopausal not using & $56(30 \%)$ & $213(31 \%)$ \\
\hline Postmenopausal using & $59(32 \%)$ & $256(37 \%)$ \\
\hline Premenopausal/unknown & $69(38 \%)$ & $221(32 \%)$ \\
\hline $\mathrm{BMI}^{\mathrm{a}}\left(\mathrm{kg} / \mathrm{m}^{2}\right)[$ mean (SD)] & $26.3(4.9)$ & $26.1(5.1)$ \\
\hline \multicolumn{3}{|l|}{ Pack-year smoked ${ }^{b}$ [n (\%)] } \\
\hline 0 (never smoker) & $111(60 \%)$ & $357(52 \%)$ \\
\hline$\leq 16$ pack-year & $18(10 \%)$ & $71(10 \%)$ \\
\hline$>16$ pack-year & $53(29 \%)$ & $258(37 \%)$ \\
\hline $\begin{array}{l}\text { Census track median income (\$) } \\
\text { ([mean (SD)] }\end{array}$ & $59,950(18,200)$ & $64,480(25,064)$ \\
\hline \multicolumn{3}{|l|}{ Region [n (\%)] } \\
\hline Northeast & $52(28 \%)$ & 233 (34\%) \\
\hline Midwest & $102(55 \%)$ & $113(16 \%)$ \\
\hline West & $12(7 \%)$ & $150(22 \%)$ \\
\hline South & $18(10 \%)$ & 194 (28\%) \\
\hline
\end{tabular}

${ }^{a}$ Obtained one cycle before diagnosis

${ }^{\mathrm{b}}$ Pack-year smoking of 16 is the population median among ever smokers 
$26.3 \mathrm{~kg} / \mathrm{m}^{2}(\mathrm{SD}=4.9)$ in the high exposure group and was $26.1 \mathrm{~kg} / \mathrm{m}^{2}(\mathrm{SD}=5.1)$ in the low radon group. Census tract-level median household income was higher in the low radon group (mean $\pm \mathrm{SD}=64,480 \pm 25,064$ ) compared to the high radon group (mean $\pm \mathrm{SD}=59$, $950 \pm 18,200$ ). In the high radon group, more than $50 \%$ of women lived in the Midwest region at the time of breast cancer diagnosis, while $16 \%$ of participants in the low radon group lived in this region. The distribution of radon concentrations in the U.S. is shown in Supplementary Figure 1 (ArcMap 10.4 (Esri, Redlands, CA)) and stratified by ER status and tissue types in Supplementary Figure 2.

\section{Single gene analysis}

In ER positive normal-adjacent samples, cumulative radon exposure was associated with differential expression of PLCH2 (negative association), a phospholipase gene involved in cellular proliferation (FDR $<5 \%$ ). We did not find statistically significant associations between cumulative radon exposure and differential gene expression in ER-positive tumor, ER-negative tumor, or ERnegative normal-adjacent samples that met FDR $<5 \%$. In Supplementary Table 1, we presented the top 10 differentially expressed genes sorted by nominal $p$ value for tumor and normal-adjacent samples. We observed same signs of directionality, similar magnitudes of effect estimates and similar ranges of $p$-values when we modeled radon as a continuous exposure metric (Supplementary Table 1). Fig. 1 shows differentially expressed genes with relatively large effect size (i.e., top 5\%, which was defined as genes with log fold change larger than the average of the 2.5th and 97.5th percentile) and had a nominal $p$ value less than 0.001 in tumor and normaladjacent samples. In ER positive normal-adjacent samples, 7 of the 11 genes that met FDR $<15 \%$ also had large effect size (i.e., top 5\%).

As sensitivity analyses, we stratified women to never smokers and women smoked $>16$ pack-years (population median of ever smokers). Among the top 10 most significant genes identified in the tumor analyses, we observed same signs of directionality and comparable magnitudes of effect estimate in the two stratified populations (Supplementary Table 2). We also observed comparable results when we restricted radon exposure 5 year prior to breast cancer diagnosis (Supplementary Table 1).

\section{Gene-set enrichment pathway analysis}

At FDR $<25 \%$, we identified two distinct biological pathways significantly enriched in ER negative breast tumor (P38MAPK signaling pathway: up-regulated) and ER

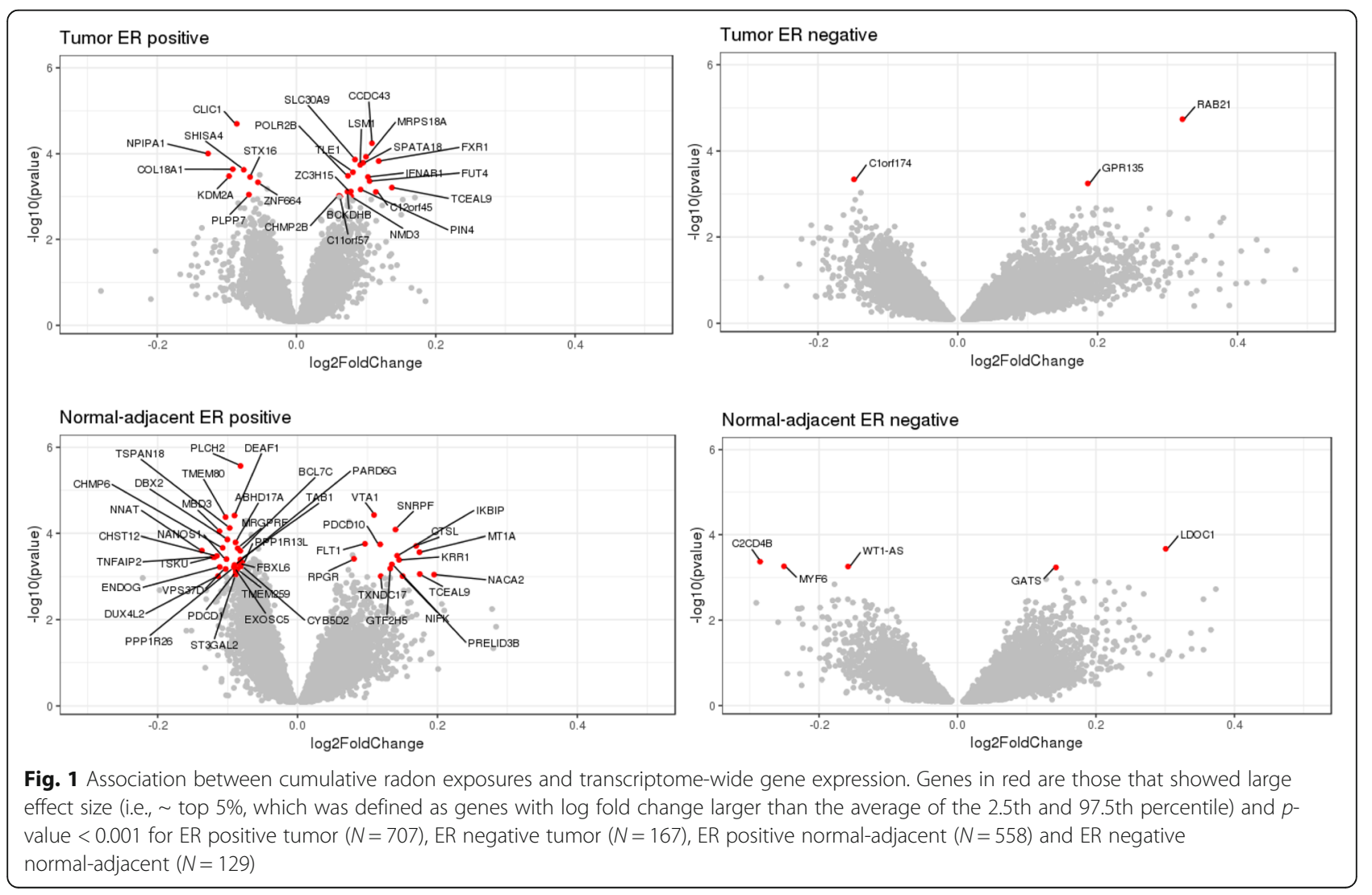


negative normal-adjacent samples (synthesis of phosphocholine: up-regulated) with higher cumulative radon exposure (Fig. 2; Supplementary Figure 3). Genes

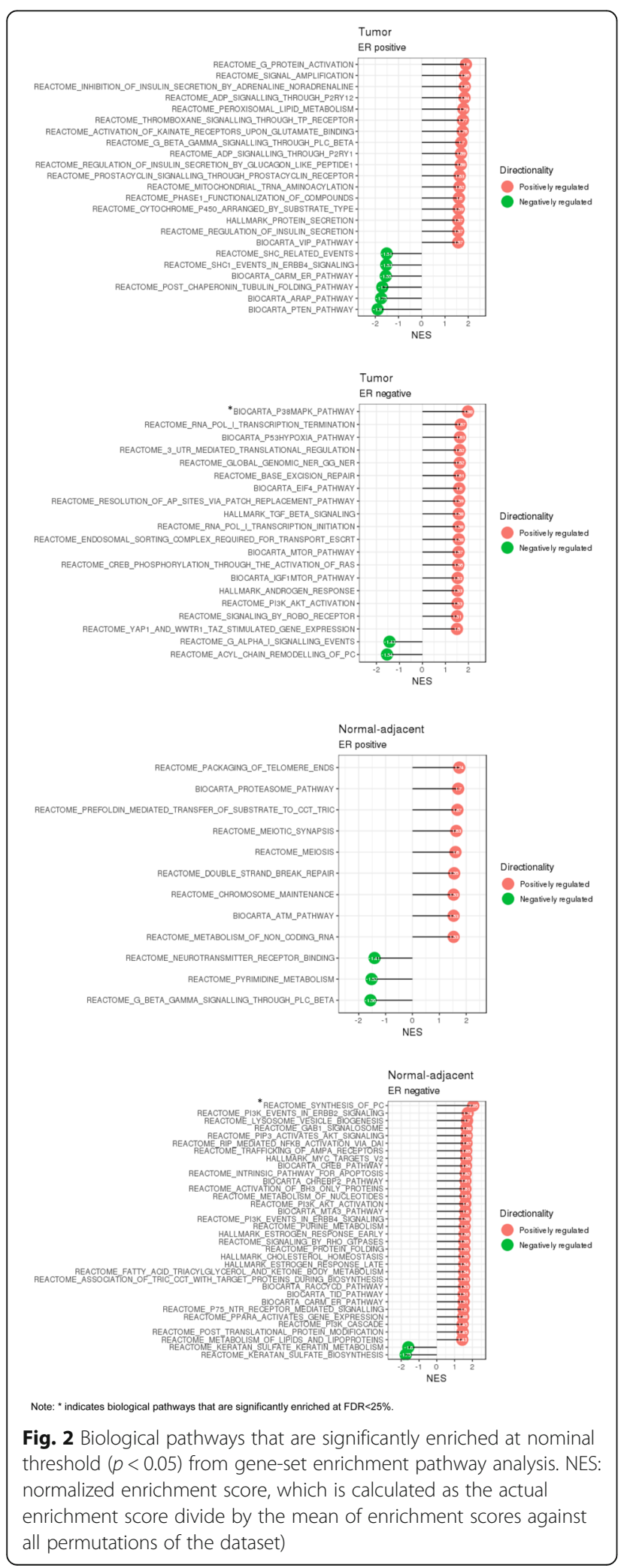

contributing to the core enrichment for P38MAPK signaling included CREB1, TGFBR1, MAPKAPK2, MKNK1, ATF2, ELK1, MEF2A, MAPKAPK5, HSPB1, RIPK1, $M E F 2 C$, RAC1, CDC42, MAPK14, TGFB3, TGFB2, STAT1, and HMGN1, while genes contributing to the core enrichment for phosphocholine synthesis included SLC44A4, PCYT1A, LPIN3, CHKB, SLC44A2, and CHKA (Fig. 3). We summarize our key findings for the single gene analysis and pathway analysis in Supplementary Table 3.

\section{Discussion}

To the best of our knowledge, this is the first prospective population-based study investigating the association between low dose radon exposure and gene expression patterns in FFPE breast tumor blocks obtained from invasive breast cancer cases. Overall, we did not see strong evidence of radon exposure being differentially associated with any single gene. However, pathway analyses identified two gene sets (P38MAPK signaling and phosphocholine synthesis) that were significantly enriched after multiple testing adjustment. As we still observed biological effects when radon was modelled at a cutoff $(2 \mathrm{pCi})$ below the EPA recommendations $(4 \mathrm{pCi})$, this suggests that radon could still possess adverse health consequences at a concentration below the current recommendations.

Radon was among the first human environmental carcinogens identified and was originally described as the chemical associated with "the wasting disease of miners" by Paracelsus in 1567 [39]. To date, it is widely accepted that radon and its progeny contribute significantly to excess lung cancer among underground miners [40, 41]. Although not nearly comparable to the high dose received by uranium miners, several case-control studies conducted in non-occupational settings showed that low dose radon exposure was associated with higher risk of lung cancer [42-46]. In fact, the National Council on Radiation Protection \& Measurements (NCRP) estimated approximately 10,000 deaths per year in the U.S., for an average annual radon exposure of $1 \mathrm{pCi} / \mathrm{L}[40$, 47]. Since inhalation is the primary route of exposure, much of the current research for radon focuses on lung cancer as the main health outcome. Nevertheless, based on its lipophilic properties, biokinetic models estimated that deliverable concentrations of radon decay products were detected in the breast and lung at an annual dose of $1000 \mathrm{~Bq} / \mathrm{L}$ (or $2.7 \times 10^{4} \mathrm{pCi} / \mathrm{L}$ ) [3]. In the NHSII, we previously observed that cumulative radon exposure, even at low doses, was associated with higher risk of ERnegative breast cancer [17]. Consistent with our previous findings, the current work identified mitogenic (P38MAPK signaling: up-regulated) and phosphocholine (synthesis of phosphocholine: down-regulated) pathways 


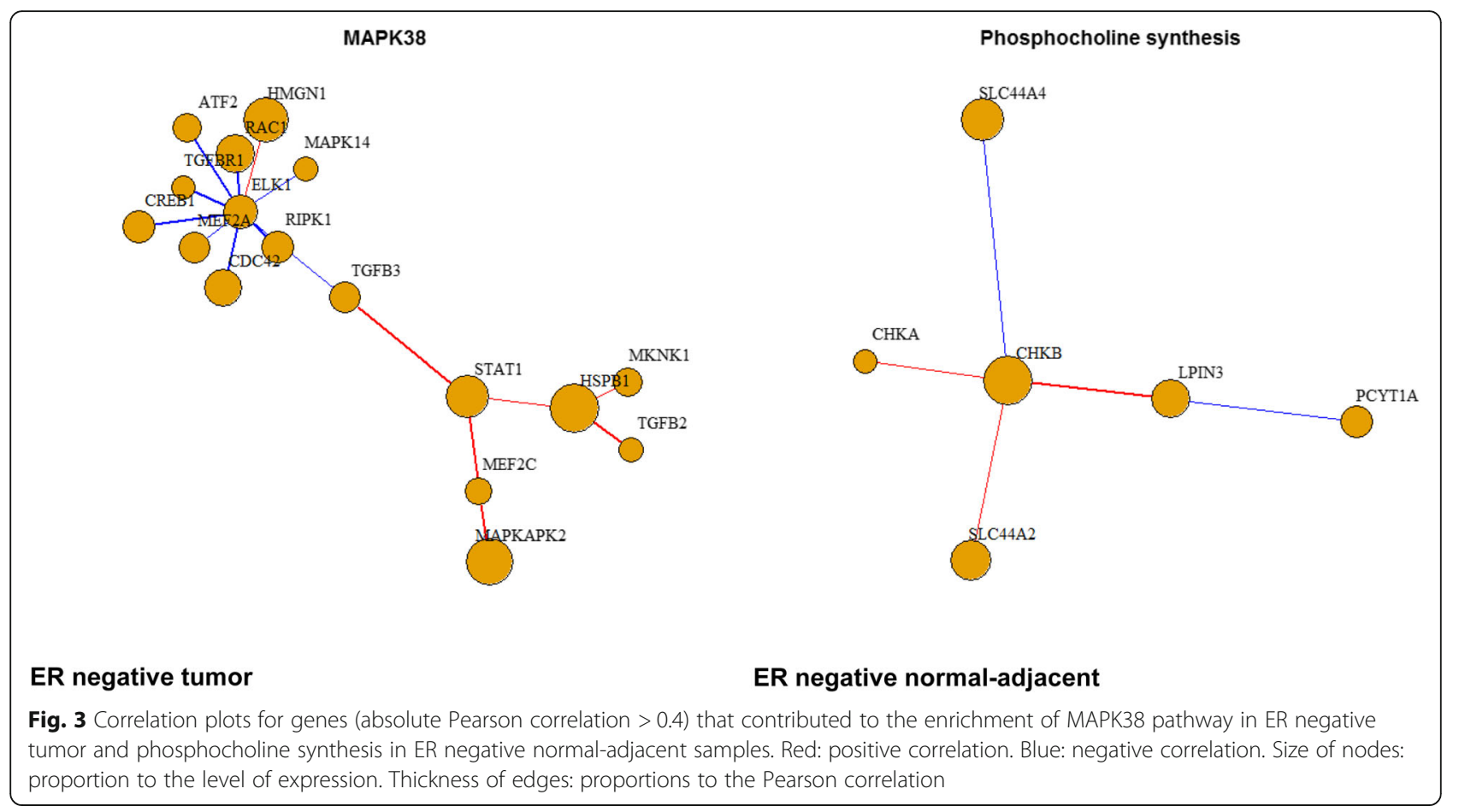

that were significantly enriched in ER-negative breast tumor and normal-adjacent tissues (FDR $<25 \%$ ).

Previous experimental studies have shown that MAPK signaling and phosphocholine biosynthesis played key roles in ionizing radiation induced tumorigenesis. In normal human diploid and tumor cell lines, low dose ionizing radiation could stimulate the MAPK pathway and enhance cell proliferation [48]. Exposure to moderate-to-low dose ionizing radiation also led to the activation of the p42/44 MAPK pathway in animal models [49]. In mammalian cell lines, p38 MAPK has been shown to govern the G2-M transition, and activation of p38 MAPK cascade is required for ionizing radiation induced G2 arrest [50]. Ionizing radiation could also destruct cellular membranes, hydrolyze sphingomyelin to generate phosphocholine, and initiate programmed cell death [51]. In population-based studies, pre-diagnostic phosphocholine has also been shown to be a reproducible biomarker for breast cancer prognosis in multiple cohort studies [52-54].

Single gene analyses identified $P L C H 2$, a member of the phospholipase $\mathrm{C}$ super family, to be associated with radon exposures in ER-positive normal-adjacent samples. PLCH2 has essential role for the cleavage of membrane phospholipids, thereby generating second messengers inositol 1,4,5-trisphosphate $(\operatorname{PtdIns}(4,5) \mathrm{P} 2)$ and 1,2-diacylglycerol (DAG) $[55,56]$. The $2 \mathrm{~s}$ messengers re important for $G$ protein coupled receptor activation. The suppression of $\mathrm{PLCH} 2$ in ER-positive normal adjacent tissue may represents an adaptive/ maladaptive response to radon exposures. Stratified analysis by smoking status (never smokers, women who smoked $\leq 16$ pack-years and women who smoked $>16$ pack-years) yielded comparable magnitudes of effect estimates, indicating that the association between radon and $P L C H 2$ did not differ by smoking status. Radon is ionizing radiation and is thought to be associated with both ER-positive and ER-negative breast cancer risks. However, since reproductive and hormonal factors may affect ER-positive breast cancer risk, the association between radon and ER-positive breast cancer risk may be masked. At the molecular level, there may still be molecular alterations associated with both ER-positive and ER-negative tumors. Our study has a number of strengths. To the best of our knowledge, this is the first prospective study to investigate radon exposure with breast cancer biology using transcriptome-wide gene expression data. We included a large number of invasive breast cancer cases. We were able to examine expression in both tumor and normal-adjacent tissues. Previous studies have suggested that the tissue surrounding tumors was morphologically and phenotypically distinct from healthy tissue, and may provide essential information for tumorigenesis [57]. Radon represents a modifiable risk factor with a relatively feasible intervention (radon remediation).

Our study also has a few limitations. Our gene expression data was obtained from FFPE tissue blocks preserved for approximately $\sim 20$ years (median year 
of diagnosis was 1999), and RNA degradation maybe of concern. We performed pilot work and showed high correlations between ESR1, PGR, and ERBB2 expression with ER, PR, and ER2 immunohistochemistry staining $[28,29]$. Our findings are unlikely to be affected by $\mathrm{x}$-ray exposures from mammographic screening, since approximately $80 \%$ of women had regular screening (i.e., in each 2 year of the follow up period before diagnosis) [58] and there was little variability by screening intensity/frequency. In our previous study, inverse probability weighting was used to create a hypothetical population in which screening was uncorrelated with all the potential risk factors of breast cancer, and results showed that small changes in effect estimates were observed for breast cancer risk factors [58]. Radon was estimated using a county-level metric that may not actually reflect individual-level exposure and we did not have indoor radon measured individually. Household radon level may differ within a county because of variations in housing characteristics, geology, and radon remediation. Nurses, as health professionals, may be aware of radon as a carcinogen and established remediations. Our radon exposure model has been applied in previous population-based studies of lung cancer, showing expected positive associations [59], which suggests that the model maybe a reasonable proxy for residential radon exposure. Additional research is needed to determine whether our findings can be confirmed in other cohorts, in particular for ERnegative breast cancer cases where sample size was modest. Our single gene and GSEA results need to be confirmed by future studies which include quantitative polymerase chain reactions (qPCR) of core enriched genes and protein biomarkers. Annual radon concentrations, which reflect geological, geographical and meteorological information in the study region, were all below $300 \mathrm{~Bq} / \mathrm{m}^{3}$. Future studies in elevated radon areas is needed to compare breast cancer characteristics. It would also be important in future work to conduct validation studies to determine the extent to which the radon exposure model is predictive of personal radon exposure.

\section{Conclusion}

To the best of our knowledge, this is the first prospective study to assess the associations between radon exposure and breast tumor and normal-adjacent tissue transcriptomes. Gene set enrichment analysis identified MAPK signaling and phosphocholine biogenesis being upregulated after multiple testing adjustment. Our findings provide further insights into the underlying molecular mechanisms by which low dose radon exposure and may impact breast cancer risk.

\section{Supplementary information}

Supplementary information accompanies this paper at https://doi.org/10. 1186/s12885-020-07184-7.

Additional file 1. Table S1. Comparison of signs of directionality, magnitude of effect estimates and p-values when modeling radon as cumulative average (i) up to the year of breast cancer diagnosis as a dichotomized variable ( $\geq 2 \mathrm{pCi} / \mathrm{L}$ vs. $<2 \mathrm{pCi} / \mathrm{L}$ ); (ii) up to the year of breast cancer diagnosis as a continuous variable; and (iii) 5 year prior to breast cancer diagnosis as a dichotomized variable ( $\geq 2 \mathrm{pCi} / \mathrm{L}$ vs. $<2 \mathrm{pCi} / \mathrm{L}$ ). Top 10 genes (sorted by $p$-value) associated with cumulative radon exposures $(\geq 2 \mathrm{pCi} / \mathrm{L}$ vs. $<2 \mathrm{pCi} / \mathrm{L})$ - estimated as cumulative averages up to the year of breast cancer diagnosis—by tumor/normal-adjacent and ER status. Table S2. Top 10 genes (sorted by p-value) associated with cumulative radon exposures - estimated as cumulative averages up to the year of breast cancer diagnosis_by tumor/normal-adjacent and ER status. Table S3. Summary of main findings. Sample size: ER positive tumor $(N=707)$, ER negative tumor ( $N=167)$, ER positive normal-adjacent tissue $(N=558)$ and $E R$ negative normal-adjacent tissue $(\mathrm{N}=129)$. Figure S1. Map of annual average radon concentration generated from ArcGIS 10.3.1. This figure is not under copyright. Figure S2. Distribution of cumulative radon concentrations for study participants. Figure S3. Gene-set enrichment analysis results (FDR $<25 \%)$.

\section{Abbreviations}

NHS: Nurses' Health Study; ER: Estrogen receptor; GIS: Geographic information system; EPA: Environmental Protection Agency; SRRS: State Residential Radon Survey; NRRS: National Residential Radon Survey; TMA: Tissue microarray; FFPE: Formalin fixed paraffin-embedded; RMA: Robust multi-array average; ATP: Affymetrix Power Tool; BMl: Body mass index; HT: Hormone therapy; FDR: False discovery rate; GSEA: Gene set enrichment analysis; MSigDB: Molecular Signature Database; NCRP: National Council on Radiation Protection \& Measurements

\section{Acknowledgements}

The authors thank all participants and coordinators of the Nurses' Health Study and the Nurses' Health Study II for their valuable contribution, and the cancer registries in the following states for their help: $A L, A Z, A R, C A, C O, C T$, $D E, F L, G A, I D, I L, I N, I A, K Y, L A, M E, M D, M A, M I, N E, N H, N J, N Y, N C, N D, O H$, OK, OR, PA, RI, SC, TN, TX, VA, WA and WY. The authors assume full responsibility for analyses and interpretation of these data.

\section{Authors' contributions}

C.P designed and conducted the research, performed the statistical analyses, interpreted the results, and drafted the manuscript. R.M.T and F.L. designed and supervised the research, and made substantial contributions to the interpretation of results, and revisions to the manuscript. N.P., T. V., Y.J.H., K.G., A. S., O. Z., P. K., S.E.H., A.H.E, and J.E.H. made significant contributions to the statistical analysis, interpretation of results and revision of the manuscript. Y.J.H., G.M.B. and C.A.R. contributed to acquisition of tissue data, and revised the manuscript. All authors have read and approved the manuscript.

\section{Funding}

This work was supported by the National Institutes of Health/National Cancer Institute (UM1 CA186107, UM1 CA176726, P01 CA87969, U19 CA148065 and R01 CA166666), National Institute of Health Epidemiology Education Training Great to NCD (NIH T32 CA09001), the Susan G. Komen for the Cure ${ }^{\oplus}$ (IIR13264020, SAC110014). Cheng Peng is supported by the Prevent Cancer Foundation postdoctoral fellowship award. R01 CA166666, and the Susan G. Komen for the Cure ${ }^{\oplus}$ (IIR13264020, SAC110014) was involved in the design of the study and data collection. No other funding body was involved in the design of the study or the collection, analysis, or interpretation of data, or in writing the manuscript.

\section{Availability of data and materials}

The data that support the findings of this study are available from the Nurses' Health Studies, however they are not publicly available. Investigators interested in using the data can request access, and feasibility will be discussed at an investigators meeting. Limits are not placed on scientific questions or methods, and there is no requirement for co-authorship. 
Additional data sharing information and policy details can be accessed at https://www.nurseshealthstudy.org/researchers.

\section{Ethics approval and consent to participate}

The study protocol was approved by the institutional review boards of the Brigham and Women's Hospital and Harvard T. H. Chan School of Public Health, and those of participating registries as required. Written informed consent was obtained from all study participants.

\section{Consent for publication}

not applicable.

\section{Competing interests}

All authors declare no competing interests.

\section{Author details}

'Channing Division of Network Medicine, Brigham and Women's Hospital, Boston, MA, USA. ²Department of Epidemiology, University of Louisville School of Public Health and Information Science, Louisville, KY, USA. ${ }^{3}$ Department of Epidemiology, Harvard T. H. Chan School of Public Health, Boston, MA, USA. ${ }^{4}$ Department of Pathology, Beth Israel Deaconess Medical Center, Harvard Medical School, Boston, MA, USA. ${ }^{5}$ Cancer Research Institute, Beth Israel Deaconess Cancer Center, Boston, MA, USA. ${ }^{6}$ Department of Biostatistics, Harvard T. H. Chan School of Public Health, Boston, MA, USA. ${ }^{7}$ Department of Biostatistics and Epidemiology, School of Public Health and Health Sciences, University of Massachusetts Amherst, Amherst, MA, USA. ${ }^{8}$ Department of Environmental Health, Harvard T. H. Chan School of Public Health, Boston, MA, USA.

\section{Received: 3 October 2019 Accepted: 15 July 2020}

\section{Published online: 28 July 2020}

\section{References}

1. Yoon JY, Lee JD, Joo SW, et al. Indoor radon exposure and lung cancer: a review of ecological studies. Ann Occup Environ Med. 2016;28:15.

2. Darby S, Hill D, Auvinen A, et al. Radon in homes and risk of lung cancer: collaborative analysis of individual data from 13 European case-control studies. BMJ. 2005:330:223.

3. Kendall GM, Smith TJ. Doses to organs and tissues from radon and its decay products. J Radiol Prot. 2002:22:389-406.

4. Robertson A, Allen J, Laney R, et al. The cellular and molecular carcinogenic effects of radon exposure: a review. Int J Mol Sci. 2013;14:14024-63.

5. Jostes RF. Genetic, cytogenetic, and carcinogenic effects of radon: a review. Mutat Res. 1996;340:125-39.

6. Evans $\mathrm{HH}$, Mencl J, Hui TE, et al. Cytotoxic and mutagenic effects of radon and radon daughters on murine $\mathrm{L} 5178 \mathrm{Y}$ lines differing in DNA repair. Radiat Res. 1993:136:57-64.

7. Lindholm C, Makelainen I, Paile W, et al. Domestic radon exposure and the frequency of stable or unstable chromosomal aberrations in lymphocytes. Int J Radiat Biol. 1999;75:921-8.

8. Meenakshi C, Mohankumar MN. Relative biological effectiveness of radon: an in vitro study using chromosome aberrations as a biomarker. Int J Radiat Biol. 2015;91:681-5.

9. Lehnert BE, Goodwin EH, Deshpande A. Extracellular factor(s) following exposure to alpha particles can cause sister chromatid exchanges in normal human cells. Cancer Res. 1997;57:2164-71.

10. Lehnert BE, Goodwin EH. A new mechanism for DNA alterations induced by alpha particles such as those emitted by radon and radon progeny. Environ Health Perspect. 1997;105(Suppl 5):1095-101.

11. Brooks AL, Khan MA, Duncan A, et al. Effectiveness of radon relative to acute $60 \mathrm{Co}$ gamma-rays for induction of micronuclei in vitro and in vivo. Int J Radiat Biol. 1994;66:801-8.

12. Lorenzo-Gonzalez M, Ruano-Ravina A, Torres-Duran M, et al. Residential radon, genetic polymorphisms in DNA damage and repair-related. Lung Cancer. 2019:135:10-5

13. Minina VI, Sinitsky MY, Druzhinin VG, et al. Chromosome aberrations in peripheral blood lymphocytes of lung cancer patients exposed to radon and air pollution. Eur J Cancer Prev. 2018;27:6-12.

14. Druzhinin VG, Sinitsky MY, Larionov AV, et al. Assessing the level of chromosome aberrations in peripheral blood lymphocytes in long-term resident children under conditions of high exposure to radon and its decay products. Mutagenesis. 2015:30:677-83.

15. Oestreicher U, Braselmann H, Stephan G. Cytogenetic analyses in peripheral lymphocytes of persons living in houses with increased levels of indoor radon concentrations. Cytogenet Genome Res. 2004;104:232-6.

16. Barbosa-Lorenzo R, Barros-Dios JM, Raices Aldrey M, et al. Residential radon and cancers other than lung cancer: a cohort study in Galicia, a Spanish radon-prone area. Eur J Epidemiol. 2016;31:437-41.

17. VoPham T, DuPre N, Tamimi RM, et al. Environmental radon exposure and breast cancer risk in the Nurses' health study II. Environ Health. 2017;16:97.

18. De Bacco F, Luraghi P, Medico E, et al. Induction of MET by ionizing radiation and its role in radioresistance and invasive growth of cancer. $J$ Natl Cancer Inst. 2011:103:645-61.

19. Bravata $V$, Minafra $L$, Russo $G$, et al. High-dose ionizing radiation regulates gene expression changes in the MCF7 breast Cancer cell line. Anticancer Res. 2015;35:2577-91.

20. Pucci M, Bravata V, Forte Gl, et al. Caveolin-1, breast cancer and ionizing radiation. Cancer Genomics Proteomics. 2015;12:143-52.

21. Eliassen $A H$, Colditz $G A$, Rosner $B$, et al. Adult weight change and risk of postmenopausal breast cancer. JAMA. 2006;296:193-201.

22. Poole EM, Tworoger SS, Hankinson SE, et al. Body size in early life and adult levels of insulin-like growth factor 1 and insulin-like growth factor binding protein 3. Am J Epidemiol. 2011;174:642-51.

23. Price PN. Predictions and maps of county mean indoor radon concentrations in the mid-Atlantic states. Health Phys. 1997;72:893-906.

24. Price PNA. Joint analysis of long- and short-term radon monitoring data from the northern U.S. Environ Int. 1996:699-714.

25. Tamimi RM, Baer HJ, Marotti J, et al. Comparison of molecular phenotypes of ductal carcinoma in situ and invasive breast cancer. Breast Cancer Res. 2008:10:R67

26. Sisti JS, Collins LC, Beck AH, et al. Reproductive risk factors in relation to molecular subtypes of breast cancer: results from the nurses' health studies. Int J Cancer. 2016;138:2346-56

27. Kensler KH, Sankar VN, Wang J, et al. PAM50 molecular intrinsic subtypes in the Nurses' health study cohorts. Cancer Epidemiol Biomark Prev. 2019;28: 798-806.

28. Wang J, Heng YJ, Eliassen AH, et al. Alcohol consumption and breast tumor gene expression. Breast Cancer Res. 2017:19:108

29. Heng YJ, Wang J, Ahearn TU, et al. Molecular mechanisms linking high body mass index to breast cancer etiology in post-menopausal breast tumor and tumor-adjacent tissues. Breast Cancer Res Treat. 2018.

30. Kensler KH, Sankar VN, Wang J, et al. PAM50 molecular intrinsic subtypes in the Nurses' health study cohorts. Cancer Epidemiol Biomark Prev. 2018;28:798.

31. Johnson WE, Li C, Rabinovic A. Adjusting batch effects in microarray expression data using empirical Bayes methods. Biostatistics. 2007;8:118-27.

32. Viswanathan AN, Feskanich D, De Vivo I, et al. Smoking and the risk of endometrial cancer: results from the Nurses' health study. Int J Cancer. 2005; 114:996-1001

33. Smyth GK. Linear models and empirical bayes methods for assessing differential expression in microarray experiments. Stat Appl Genet Mol Biol. 2004;3.

34. EPA. A Citizen's Guide to Radon: The Guide to Protecting Yourself and Your Family from Radon. EPA402/K-12/002|2016| www.epa.gov/radon. https:// www.epa.gov/sites/production/files/2016-12/documents/2016_a_citizens guide_to_radon.pdf.

35. EPA Assessment of Risks fromRadon in Homes in Agency USEP (ed). Office of Radiation and Indoor Air United States Environmental Protection Agency Washington, DC 20460, 2003.

36. Leek JT, Storey JD. Capturing heterogeneity in gene expression studies by surrogate variable analysis. PLoS Genet. 2007;3:1724-35.

37. YH YB. Controlling the false discovery rate: a practical and powerful approach to multiple testing. J Royal Stat Soc Series B. 1995;57:289-300.

38. Subramanian A, Tamayo P, Mootha VK, et al. Gene set enrichment analysis: a knowledge-based approach for interpreting genome-wide expression profiles. Proc Natl Acad Sci U S A. 2005;102:15545-50.

39. Luch A. Nature and nurture - lessons from chemical carcinogenesis. Nat Rev Cancer. 2005:5:113-25.

40. Harley $\mathrm{NH}$, Harley $\mathrm{JH}$. Potential lung cancer risk from indoor radon exposure. CA Cancer J Clin. 1990:40:265-75.

41. Lubin JH, Boice JD Jr, Edling C, et al. Lung cancer in radon-exposed miners and estimation of risk from indoor exposure. J Natl Cancer Inst. 1995:87: 817-27. 
42. Schoenberg J. KJ: a case-control study of radon and lung cancer among New Jersey women, Phase I: New Jersey State Department of Health; 1989.

43. Auvinen A, Makelainen I, Hakama M, et al. Indoor radon exposure and risk of lung cancer: a nested case-control study in Finland. J Natl Cancer Inst. 1996;88:966-72.

44. Schoenberg JB, Klotz JB, Wilcox HB, et al. Case-control study of residential radon and lung cancer among New Jersey women. Cancer Res. 1990;50: 6520-4.

45. Barros-Dios JM, Barreiro MA, Ruano-Ravina A, et al. Exposure to residential radon and lung cancer in Spain: a population-based case-control study. Am J Epidemiol. 2002;156:548-55.

46. Lorenzo-Gonzalez M, Ruano-Ravina A, Torres-Duran M, et al. Lung cancer and residential radon in never-smokers: a pooling study in the northwest of Spain. Environ Res. 2019;172:713-8.

47. National Research Council, Evaluation of Guidelines for Exposures to Technologically Enhanced Naturally Occurring Radioactive Materials. Washington (DC), 1999.

48. Suzuki K, Kodama S, Watanabe M. Extremely low-dose ionizing radiation causes activation of mitogen-activated protein kinase pathway and enhances proliferation of normal human diploid cells. Cancer Res. 2001;61: 5396-401.

49. Kutanzi K, Kovalchuk O. Exposure to estrogen and ionizing radiation causes epigenetic dysregulation, activation of mitogen-activated protein kinase pathways, and genome instability in the mammary gland of $\mathrm{ACl}$ rats. Cancer Biol Ther. 2013;14:564-73.

50. Wang X, McGowan CH, Zhao M, et al. Involvement of the MKK6-p38gamma cascade in gamma-radiation-induced cell cycle arrest. Mol Cell Biol. 2000;20: 4543-52.

51. Haimovitz-Friedman A, Kan CC, Ehleiter D, et al. lonizing radiation acts on cellular membranes to generate ceramide and initiate apoptosis. J Exp Med. 1994;180:525-35.

52. Katz-Brull R, Seger D, Rivenson-Segal D, et al. Metabolic markers of breast cancer: enhanced choline metabolism and reduced choline-etherphospholipid synthesis. Cancer Res. 2002;62:1966-70.

53. Xu X, Gammon MD, Zeisel SH, et al. High intakes of choline and betaine reduce breast cancer mortality in a population-based study. FASEB J. 2009; 23:4022-8.

54. Cho E, Holmes MD, Hankinson SE, et al. Choline and betaine intake and risk of breast cancer among post-menopausal women. Br J Cancer. 2010;102: 489-94.

55. Dusaban SS, Purcell NH, Rockenstein E, et al. Phospholipase C epsilon links $G$ protein-coupled receptor activation to inflammatory astrocytic responses. Proc Natl Acad Sci U S A. 2013;110:3609-14.

56. Citro $S$, Malik S, Oestreich EA, et al. Phospholipase Cepsilon is a nexus for rho and rap-mediated $\mathrm{G}$ protein-coupled receptor-induced astrocyte proliferation. Proc Natl Acad Sci U S A. 2007;104:15543-8.

57. Aran D, Camarda R, Odegaard J, et al. Comprehensive analysis of normal adjacent to tumor transcriptomes. Nat Commun. 2017:8:1077.

58. Cook NR, Rosner BA, Hankinson SE, et al. Mammographic screening and risk factors for breast cancer. Am J Epidemiol. 2009:170:1422-32.

59. Turner MC, Krewski D, Chen Y, et al. Radon and lung cancer in the American Cancer Society cohort. Cancer Epidemiol Biomark Prev. 2011;20: $438-48$

\section{Publisher's Note}

Springer Nature remains neutral with regard to jurisdictional claims in published maps and institutional affiliations.

\section{Ready to submit your research? Choose BMC and benefit from}

- fast, convenient online submission

- thorough peer review by experienced researchers in your field

- rapid publication on acceptance

- support for research data, including large and complex data types

- gold Open Access which fosters wider collaboration and increased citations

- maximum visibility for your research: over $100 \mathrm{M}$ website views per year

At BMC, research is always in progress.

Learn more biomedcentral.com/submissions 